www.volsu.ru

DOI: https://doi.org/10.15688/jvolsu3.2018.1.9

UDC 332.142 .2

LBC 65.32

\title{
SPECIFICITY OF INSTITUTIONAL FACTORS' INFLUENCE ON THE DEVELOPMENT OF SPECIAL ECONOMIC ZONES IN THE RUSSIAN FEDERATION
}

\author{
Svetlana G. Pyankova \\ Ural State University of Economics, Ekaterinburg, Russian Federation \\ Olga T. Ergunova \\ Ural State University of Economics, Ekaterinburg, Russian Federation \\ Inna A. Mitrofanova \\ Volgograd State Technical University, Volgograd, Russian Federation
}

\begin{abstract}
The article explores the features of the functioning of special economic zones, which are an integral part of significant changes in the institutional structure of the regional level of management in the Russian Federation. This issue has been studied by domestic and foreign economists for several decades, but at the present time there is no single conceptual apparatus for special economic zones. This is due to the different views and goals put by individual specialists in the term under investigation. The article provides the assessment of the activities of special economic zones (SEZ) of production-industrial type, as well as the analysis of their functioning in Russia. The research object is represented by the region's economy, and the subject - by special economic zones of production-industrial type. The relevance of the study is determined by its systematic approach to the analysis of the experience of SEZ functioning in Russia and in developed countries; by identifying the institutional factors constraining their development and developing recommendations to increase the efficiency of special economic zones. The article substantiates the methodological approaches to the content of special economic zoning, and develops a number of practical recommendations to improve the effectiveness of SEZ management, taking into account the territorial features of facilities location. The approaches presented in the article are aimed at realizing the potential of special economic zones - increasing investment in facilities, applying modern technical developments, the possibility of organizing clusters, which will ensure high competitiveness of the regions.

$\stackrel{\infty}{\circ} \quad$ Key words: social and economic development, institute of regional development, mezo-level, public-private N partnership, special economic zone, production-industrial type, cluster.

\section{СПЕЦИФИКА ВЛИЯНИЯ ИНСТИТУЦИОНАЛЬНЫХ ФАКТОРОВ} НА РАЗВИТИЕ ОСОБЫХ ЭКОНОМИЧЕСКИХ ЗОН В РОССИЙСКОЙ ФЕДЕРАЦИИ
\end{abstract}

\section{Светлана Григорьевна Пьянкова}

Уральский государственный экономический университет, г. Екатеринбург, Российская Федерация

\section{Ольга Титовна Ергунова}

Уральский государственный экономический университет, г. Екатеринбург, Российская Федерация

\section{Инна Алексеевна Митрофанова}

Волгоградский государственный технический университет, г. Волгоград, Российская Федерация 


\section{УПРАВЛЕНИЕ ЭКОНОМИЧЕСКИМ РАЗВИТИЕМ}

Аннотация. В статье исследуются особенности функционирования свободных экономических зон, являющихся неотъемлемой частью существенных изменений в институциональной структуре регионального уровня хозяйствования в Российской Федерации. Данный вопрос изучается отечественными и зарубежными экономистами в течение нескольких десятков лет, однако к настоящему времени отсутствует единый понятийный аппарат в отношении особых экономических зон. Это обусловлено различными взглядами и целями, вкладываемыми отдельными специалистами в исследуемое понятие. В статье проводится оценка деятельности особых экономических зон (ОЭЗ) производственно-промышленного типа (ППТ), анализ результатов их функционирования в России. В качестве объекта исследования рассмотрена экономика региона, а к субъекту отнесены производственно-промышленные ОЭЗ. Актуальность исследования определяется его системным подходом к анализу опыта функционирования ОЭЗ в России и в развитых странах, выявлении институциональных факторов, сдерживающих их развитие, в выработке рекомендаций, позволяющих увеличить эффективность работы особых экономических зон. В статье проведено обоснование методических подходов к содержанию особого экономического зонирования, а также разработан ряд практических рекомендаций, позволяющих повысить эффективность управления ОЭЗ, учитывая территориальные особенности расположения объекта. Представленные в статье подходы направлены на реализацию потенциала свободных экономических зон: увеличение инвестирования в объекты, применение современных технических разработок, возможность организации кластеров, что обеспечит высокую конкурентоспособность регионов.

Ключевые слова: социально-экономическое развитие, институт регионального развития, мезоуровень, государственно-частное партнерство, особая экономическая зона, производственно-промышленный тип, кластер.

В настоящее время свободные экономические зоны являются неотъемлемой частью существенных изменений в институциональной структуре регионального уровня хозяйствования, при этом номинально данные зоны предназначены для обеспечения диверсификации экономики субъектов Российской Федерации, призваны повысить инвестиционную привлекательность регионов, обеспечить открытый доступ к необходимым ресурсам, а также способствовать развитию государственно-частного партнерства (ГЧП), в том числе в сфере малого и среднего бизнеса.

Современные представления о влиянии функционирования региональных институтов развития со всей остротой ставят вопрос о необходимости эффективного функционирования свободных экономических зон в условиях роста издержек пространственного развития в связи с ускорением технологической эволюции, сокращением цикла смены технологических укладов, возрастающей ролью в экономике инновационных отраслей, развитие которых мало связано с «жесткими» факторами размещения. В связи с этими положениями представляет особый интерес опыт функционирования ОЭЗ в России, выявление институциональных факторов, сдерживающих их развитие, выработка рекомендаций, позволяющих расширить государственно-частное партнерство в регионах РФ, способствующее более высокому уровню конкурентоспособности и производительности труда.

Для оценки влияния ОЭЗ на развитие региональной экономики авторами в качестве объекта исследования рассмотрена региональная экономика, субъектом выступили ОЭЗ промышленно-производственного типа (ППТ), так как, по мнению авторов, именно промышленно-производственные ОЭЗ имеют наибольшую перспективу развития и соответствуют интересам государства в развитии высокотехнологичных производств. Исключение из анализа зон технико-внедренческого типа принято по причине того, что данные институты не так рентабельны, как первые, так как их деятельность больше связана с научно-исследовательской деятельностью, которая в России поддерживается менее интенсивно, чем производство, и для крупных инвесторов еще не выработан уровень лояльности к этой деятельности. Регионы по своей экономической и политической деятельности являются наглядной проекцией государства. В их интенсивном развитии и кроется успех государства. Поэтому степень значимости региона занижать нельзя.

Применение техники анализа к конкретной особой экономической зоне проведено с использованием идей, изложенных в трудах T. Dhingra, T. Singh \& A. Sinha [8], P. Tracey, J. B. Heide, S. J. Bell \& P. Governance [16], Ch. Hsiao \& Y. Shen [10], B.-G. Park [13], 
J. Wang [17], I. Gulbis \& S. Geipele [9]. В источниках встречаются разные определения для обозначения явлений, относящихся к особым экономическим зонам. Например, «особая экономическая зона», «свободная экономическая зона», «специальная экономическая зона»; в других источниках можно встретить и иные обозначения, такие как, например, «оффшорные зоны», «зоны свободной торговли». Несогласованность в использовании условного обозначения термина приводит к трудностям в поиске информации, сравнительном анализе особых экономических зон разных стран.

Содержательно-теоретическая неопределенность есть следствие разнонаправленности векторов научной мысли применительно к ОЭЗ. В трудах В.В. Березенкова, В.И. Гайдука [3], Т. Dhingra, T. Singh \& A. Sinha [8] ОЭ3 понимаются как интернациональные экономические формирования, которые приобрели глобальный характер, охватив практически все страны мира, включая богатые и бедные. С их помощью происходит весьма интенсивная интеграция целых регионов в систему мирохозяйственных связей, что в значительной степени способствует развитию экономики отдельных регионов [14]. В работах Р. Tracey, J.B. Heide, S.J. Bell \& P. Governance [16], M.-S. Hsu, Y.-L. Lai \& F.-J. Lin [11] указывается на то, что свободные экономические зоны создают потенциал для будущей кластеризации, что является одним из инструментов регионального развития. Идентификация кластеров является ценным инструментом для понимания региональной экономики и реализации успешных стратегий развития [7]. Кластеры - это путь к повышению конкурентных преимуществ региональной экономики. Кластеры уменьшают неопределенность и обеспечивают доступ к необходимым ресурсам (финансовый капитал и компетентность / знания) в периоды кризисов [15].

Ch. Hsiao \& Y. Shen [10], B.-G. Park [13] в своих работах дают следующее определение ОЭЗ: территория государства (государств), являющаяся составной частью хозяйственного комплекса страны (групп стран), где обеспечивается производство и распределение общественного продукта для достижения определенной и конкретной общенациональной интегрированной, корпоративной цели с ис- пользованием специальных механизмов регулирования общественно-экономических отношений производства и распределения, способных к диффузному расширению ее границ.

P.И. Зименковым [4] и J. Wang [17] дано описание ОЭЗ как части национального экономического пространства, в котором для иностранного и местного бизнеса применяется отдельный льготный хозяйственный режим, который применяется исключительно в пределах обозначенного объекта и позволяет решить множество социально-экономических задач и проблем научно-технического плана.

Эти определения имеют схожий смысл, но отличаются расстановкой акцентов. Первое определение рассматривает ОЭЗ как кластеры, объединяющие в себе производства различного характера. Особые экономические зоны рассматриваются как один из инструментов глобализации. Рассматривая второе определение, можно отметить, что оно не только носит многоаспектный характер и отличается сложностью к восприятию, но и имеет некоторые неточности. При скрупулезном рассмотрении можно найти противоречие между определением ОЭЗ как территориального объекта страны или нескольких стран и установлением общенациональной цели [1]. В этом же ключе ОЭЗ рассмотрены в качестве составной части хозяйственного комплекса одного либо нескольких государств. Для последней части определения, равно как и для характеристик типа «интегрированная и корпоративная», требуется более понятное и точное пояснение [12]. Некоторые авторы считают, что термин «ОЭЗ» точнее и подробнее описывается в третьем определении и схож с их точкой зрения [2].

Проведенное исследование различных определений и мнений относительно ОЭЗ позволило авторам дать собственное определение, которое, в их понимании, более полно раскрывающее данный вопрос. Особая экономическая зона - это обособленная часть территории страны, с организованной на ней институциональной инфраструктурой и применением для нее обособленного правового и административного режима. Он обеспечивает регулирование экономических отношений внутри зоны и с внешними контрагентами и одновременно является инструментом ее развития. 
В определение авторами также было включено понятие, относящееся к второстепенной цели ОЭЗ, определяющее ее развитие с позиции экономики недвижимости и девелопмента именно того региона, к которому она территориально принадлежит, а не только с позиции рыночной экономики и промышленности.

Ключевыми свойствами и признаками ОЭЗ как анализируемой единицы являются:

1) принадлежность и прямая связь с государством, вторичность ОЭЗ по отношению к последнему;

2) обособленность - четкие границы, определенные государством и строго отделяющие объект от остальной территории страны;

3) наличие институциональной инфраструктуры, поскольку отсутствие таковой может свидетельствовать о случайном характере отличий объекта от остальной части хозяйственного комплекса;

4) специальный правовой и административный режим, отличающийся от общего режима, имеющего силу в данной стране, но необязательно исключительный (единственный в своем роде);

5) регулирование взаимоотношений между институтами и хозяйствующими субъектами, осуществляющими свою деятельность внутри ОЭЗ, в том числе внешнеэкономических с точки зрения ОЭЗ связей.

Наличие именно данного набора признаков необходимо и достаточно для отнесения объекта к разряду особых экономических зон с целью его дальнейшего исследования.

Федеральный закон «Об особых экономических зонах» № 116-ФЗ от 22.07.2005 устанавливает наличиепромышленно-производственных, технико-внедренческих, туристскорекреационных и портовых разновидностей особых экономических зон. В таблице 1 представлены краткие характеристики типов различных объектов.

Непосредственно от объемов инвестирования зависит развитие зоны. В последнее время предпринимаются попытки усилить роль региональных бюджетов в финансировании ОЭЗ. К примеру, ФЗ «О федеральном бюджете на 2016 год» № 359-Ф3 от 14.12.2015 предусматривал снижение отчислений из бюджета в пользу ОЭЗ. И если по данным за 2011 г. всего было выделено 15,7 млрд руб., то за период 2012-2013 гг. сумма финансирования снизилась до 6 млрд рублей. По данным за 2016 г., на все виды ОЭЗ было выделено всего 4,35 млрд рублей [5; 6].

Наряду с источниками бюджетного финансирования, немалую роль в повышении эффективности функционирования объектов играет инвестирование. Как показал анализ, в отношении выполнения частными инвесторами своих обязательств складывается довольно сложное положение (см. табл. 2). Анализ представленных данных показывает, что в ОЭЗ промышленного и туристического типов

Основные экономические показатели ОЭЗ России с 2006 по 2016 г.

Таблийа 1 (нарастающим итогом)

\begin{tabular}{|c|c|c|c|c|c|c|}
\hline \multirow[t]{2}{*}{ Зоны } & \multirow[b]{2}{*}{$\begin{array}{c}\text { Количество } \\
\text { резидентов } \\
\text { (в том числе } \\
\text { потенциаль- } \\
\text { ных), ед. } \\
\end{array}$} & \multirow{2}{*}{$\begin{array}{l}\text { Создано } \\
\text { рабочих } \\
\text { мест, ед. }\end{array}$} & \multirow[b]{2}{*}{$\begin{array}{c}\text { Фактический } \\
\text { объем инве- } \\
\text { стиций рези- } \\
\text { дентов, } \\
\text { млн руб. }\end{array}$} & \multirow{2}{*}{$\begin{array}{c}\text { Объем де- } \\
\text { нежной } \\
\text { выручки, } \\
\text { млн руб. }\end{array}$} & \multicolumn{2}{|c|}{ Денежная выручка } \\
\hline & & & & & $\begin{array}{l}\text { на } 1 \text { руб. } \\
\text { инвести- } \\
\text { ций, руб. }\end{array}$ & $\begin{array}{c}\text { на одного } \\
\text { работника, } \\
\text { млн руб. }\end{array}$ \\
\hline ОЭЗ ППТ «Алабуга» & 58 & 5434 & 97827,19 & 168136,36 & 1,70 & 30,90 \\
\hline ОЭЗ ППТ «Липецк» & 23 & 2460 & 24148,00 & 23941,00 & 0,99 & 9,70 \\
\hline ОЭЗ ППТ «Тольятти» & 19 & 574 & 8704,00 & 574,00 & 0,06 & 1,00 \\
\hline ОЭЗ ППТ «Титановая долина» & 11 & 21 & 3,00 & - & - & - \\
\hline Прочие ОЭЗ & 97 & 101 & 271,00 & - & - & - \\
\hline Итого по ОЭЗ ППТ & 198 & 8590 & 130953,19 & 192651,36 & 1,47 & 22,4 \\
\hline $\begin{array}{l}\text { В целом по технико-внедрен- } \\
\text { ческим ОЭЗ }\end{array}$ & 402 & 4509 & 22890 & 19342 & 0,85 & 4,30 \\
\hline $\begin{array}{l}\text { В целом по туристско-рекреа- } \\
\text { ционным ОЭ3 }\end{array}$ & 67 & 110 & 1048 & 125 & 0,12 & 0,10 \\
\hline В целом по портовым ОЭЗ & 13 & 24 & 108 & - & - & - \\
\hline Итого по всем ОЭЗ & 681 & 13233 & 154999,19 & 212118,36 & 1,37 & 16,03 \\
\hline
\end{tabular}

Примечание. Источник: [6]. 
Соотношение планируемых и фактических вложений частных инвесторов (нарастающим итогом к 2015 г.)

\begin{tabular}{|l|c|c|c|}
\hline \multicolumn{1}{|c|}{ Типы зон } & $\begin{array}{c}\text { Планируемые инве- } \\
\text { стиции, млн руб. }\end{array}$ & $\begin{array}{c}\text { Фактические вло- } \\
\text { жения, млн руб. }\end{array}$ & $\begin{array}{c}\text { Отношение пла- } \\
\text { на к факту, \% }\end{array}$ \\
\hline $\begin{array}{l}\text { Промышленно-производственные } \\
\text { зоны }\end{array}$ & 120000,00 & 112658,00 & 94,00 \\
\hline Технико-внедренческие зоны & 22500,00 & 28291,00 & 121,00 \\
\hline Туристско-рекреационные зоны & 7500,00 & 1271,00 & 17,00 \\
\hline Портовые зоны & 120,00 & 125,00 & 103,00 \\
\hline & 150120,00 & 142345,00 & 94,82 \\
\hline
\end{tabular}

Примечание. Источник: [6].

наблюдается разрыв между заявленными резидентами инвестициями и фактически вложенными в производственный процесс. Лучшее положение складывается в технико-внедренческих зонах, что немного удивительно, ведь в промышленно-производственных зонах более быстрый оборот продукции и выше денежная выручка, что выступает стимулирующим фактором для инвесторов.

Таким образом, планирование и строительство таких объектов, как особые экономические зоны, требует тщательного подхода и кропотливой работы проектных менеджеров. Нельзя надеяться, что можно точечно создать подобный проект, не прибегая к изменению уже сложившихся норм, правил, укладов. Если регион берет на себя ответственность возводить на своей территории такого рода объект, он должен понимать свои затраты, сроки окупаемости, цели проекта. И подходить к реализации нужно системно. Для начала необходима продуманная регламентирующая деятельность экономической зоны документация, не только на федеральном уровне, но и на региональном. Данные объекты должны быть реактивом для создания возможностей малому и среднему бизнесу, должны способствовать занятости населения, созданию дополнительных рабочих мест, создавать новые медицинские учреждения с льготными условиями, а также специализированные образовательные учреждения, готовящие высококлассных специалистов под необходимые экономической зоне направления.

Нельзя забывать, что зоны промышленно-производственного типа создаются для решения широкого круга задач. Причем создавать их можно достаточно быстро на тер- ритории любого региона Федерации, не возлагая дополнительную нагрузку на бюджеты всех уровней. Как считают авторы, решение вопросов, связанных с бесплатным предоставлением земельных участков, подготовкой инженерных сетей и льготным техническим присоединением к ним, является наиболее перспективным механизмом создания таких объектов. В силу этого создание промышленно-производственных зон как самостоятельных инструментов экономического развития должно стать одним из приоритетов при формировании промышленной политики государства и региона. Внедрение на их базе технологической и производственной специализации позволит создать эффективные отраслевые кластеры, что приведет к существенному увеличению конкурентоспособности выпускаемых товаров и услуг, выходу на новые рынки сбыта продукции.

Промышленно-производственная зона это не просто особая экономическая зона с определенными налоговыми льготами, а территория, на которой развиты транспортная сеть, инфраструктура, автономное электроснабжение, то есть все элементы, способствующие развитию непрерывного производства конкурентоспособной качественной продукции и комплексного развития территории.

Несмотря на создание региональных институтов развития по взаимодействию с инвесторами, субъекты сталкиваются с трудностями, касающимися предоставления в особом порядке земельных участков для создания ОЭЗ промышленно-производственного типа, сопровождения административных процедур в режиме «одного окна», а также налогообложения при реализации инфраструктурных проектов. Решение вышеназванных про- 
блем видится в необходимости перехода к более гибкой системе планирования и управления, которое обусловливает важность создания новых управленческих схем и механизмов, ориентированных на развитие особых экономических зон.

Основными принципами создания таких новых схем и механизмов управления должны стать:

1) При формировании межрегиональных организационных структур целесообразно учесть опыт формирования Еврорегионов (по размерам и масштабам экономики часто сопоставимых с макрорегионами России), а также исторический пример - «Администрация долины реки Теннеси», созданная для ряда антикризисных мероприятий в годы Великой экономической депрессии в США.

2) Возможность формирования проектных администраций как по инициативе «сверху», так и по инициативе «снизу».

3) Совершенствование механизмов взаимодействия государственных, региональных и муниципальных органов власти, некоммерческих организаций и других институтов гражданского общества и бизнес-структур, действующих на территории нескольких субъектов Российской Федерации и/или муниципальных образований.

В целом предстоит обеспечить координацию деятельности административных структур, действующих в сфере государственной, региональной и муниципальной власти, бизнеса и гражданского общества, сразу на всех пространственных уровнях: с одной стороны, улучшить координацию существующих структур, с другой - создать механизм формирования новых, призванных обеспечить адекватное управление и координацию социально-экономического развития на недостающих в настоящий момент пространственных уровнях (в первую очередь координацию хозяйственного развития на межрегиональном и межмуниципальном уровне).

Необходимо формирование нормативной и организационной базы обеспечения гибкого взаимодействия между разномасштабными структурами разных подструктур институциональной территориальной структуры страны - зонами ответственности государственных и региональных органов власти, зонами дея- тельности коммерческих фирм, некоммерческих организаций и других институтов гражданского общества. Это потребует радикального усложнения всей территориальной институциональной структуры страны, однако такой переход назрел и будет адекватным ответом на вызовы ускорения социально-экономического развития.

\section{СПИСОК ЛИТЕРАТУРЫ}

1. Альба, С. Сравнительный анализ подходов к понятиям особых экономических зон и оффшорных зон / С. Альба // Финансы. - 2016. - № 3. C. $119-123$.

2. Белоусов, В. И. Развитие особых экономических зон регионального уровня / В. И. Белоусов // Региональная экономика. - 2016. - № 3. C. 54-58.

3. Березенков, В. В. Коммерческая деятельность / В. В. Березенков, В. И. Гайдук, П. В. Михайлушкин. - Краснодар : Атри, 2010. - 254 с.

4. Зименков, Р. И. Свободные экономические зоны / Р. И. Зименков. - М. : ЮНИТИ-ДАНА, 2014. $224 \mathrm{c}$.

5. Матушкина, Н. Опыт реализации механизмов территориального развития в регионах России / Н. Матушкина // Региональная экономика. - 2016. № 12. - C. 4-17.

6. Особые экономические зоны // Сайт Министерства экономического развития России. Электрон. текстовые дан. - Режим доступа: http:// economy.gov.ru/minec/activity/sections/sez/main/ index. - Загл. с экрана.

7. Argüelles, M. A New Approach to the Identification of Regional Clusters: Hierarchical Clustering on Principal Components / M. Argüelles, C. Benavides, I. Fernández // Applied Economics. 2014. - Vol. 46, iss. 21. - P. 2511-2519.

8. Dhingra, T. Location Strategy for Competitiveness of Special Economic Zones: A Generic Framework for India / T. Dhingra, T. Singh, A. Sinha // Competitiveness Review: An International Business Journal. - 2009. - Vol. 19, iss. 4. - P. 272-289.

9. Gulbis, I. Social Partner Involvement in Latvia Special Economic Zones / I. Gulbis, S. Geipele // Baltic Journal of Real Estate Economics and Construction Management. - 2016. - № 4. - P. 145-152.

10. Hsiao, Ch. Foreign Direct Investment and Economic Growth - the Importance of Institutions and Urbanization / Ch. Hsiao, Ya. Shen // Economic Development and Cultural Change. - 2003. - Vol. 51, iss. 4. - P. 883-896.

11. Hsu, M.-S. Effects of Industry Clusters on Company Competitiveness: Special Economic Zones 
in Taiwan / M.-S. Hsu, Yu.-L. Lai, F.-Jy. Lin // Review of Pacific Basin Financial Markets and Policies. 2013. - Vol. 16, iss. 3. - P. 45-47.

12. Levien, M. The Land Question: Special Economic Zones and the Political Economy of Dispossession in India / M. Levien // The Journal of Peasant Studies. - 2012. - Vol. 39. - P. 3-4.

13. Park, B.-G. Spatially Selective Liberalization and Graduated Sovereignty: Politics of Neo-liberalism and 'Special Economic Zones' in South Korea / B.-G. Park // Political Geography Description. - 2005. - Vol. 24, iss. 7. - P. 850-873.

14. Schweinberger, A. Special Economic Zones and Quotas on Imported Intermediate Goods: a Policy Proposal / A. Schweinberger // Oxford Economic Papers. - 2003. - Vol. 55, iss. 4. - P. 696-715.

15. Skelholt, A. Coping with Economic Crises The Role of Clusters / A. Skelholt, T. Thune // European Planning Studies. - 2013. - Vol. 22, iss. 10. - P. 1993-2010.

16. Tracey, P. Bringing 'Place' Back. Regional Clusters, Project Governance, and New Product Outcomes / P. Tracey, J. B. Heide, S. J. Bell, P. Governance // Journal of Marketing. - 2014. - Vol. 78. - P. 1-16. DOI: https://doi.org/10.1509/jm.13.0524.

17. Wang, J. The Economic Impact of Special Economic Zones: Evidence from Chinese Municipalities / J. Wang // Journal of Development Economics. - 2013. - Vol. 101. - P. 133-147.

\section{REFERENCES}

1. Alba S. Sravnitelnyy analiz podkhodov k ponyatiyam osobykh ekonomicheskikh zon i offshornykh zon [Comparative Analysis of Approaches to the Concepts of Special Economic Zones and Offshore Zones]. Finansy, 2016, no. 3, pp. 119-123.

2. Belousov V.I. Razvitie osobykh ekonomicheskikh zon regionalnogo urovnya [Development of Special Economic Zones of Regional Level ]. Regionalnaya ekonomika, 2016, no. 3, pp. 54-58.

3. BerezenkovV.V., Gayduk V.I., Mikhaylushkin P.V. Kommercheskaya deyatelnost [Commercial Activity]. Krasnodar, Atri Publ., 2010.254 p.

4. Zimenkov R.I. Svobodnye ekonomicheskie zony [Special Economic Zones]. Moscow, YuNITIDANA Publ., 2014. 224 p.

5. Matushkina N. Opyt realizatsii mekhanizmov territorialnogo razvitiya $\mathrm{v}$ regionakh Rossii [Experience of the Implementation of the Mechanisms of Territorial Development in the Regions of Russia]. Regionalnaya ekonomika, 2016, no. 12, pp. 4-17.
6. Osobyye ekonomicheskiye zony [The Special Economic Zones]. Sayt Ministerstva ekonomicheskogo razvitiya Rossii [The Website of the Ministry of Economic Development of Russia]. URL: http:// economy.gov.ru/minec/activity/sections/sez/main/index.

7. Argüelles M., Benavides C., Fernández I. A New Approach to the Identification of Regional Clusters: Hierarchical Clustering on Principal Components. Applied Economics, 2014, no. 46, iss. 21, pp. 2511-2519.

8. Dhingra T., Singh T., Sinha A. Location Strategy for Competitiveness of Special Economic Zones: A Generic Framework for India: Competitiveness Review. International Business Journal, 2009, no. 19, iss. 4, pp. 272-289.

9. Gulbis I., Geipele S. Social Partner Involvement in Latvia Special Economic Zones. Baltic Journal of Real Estate Economics and Construction Management, 2016, no. 4, pp. 145-152.

10. Hsiao Ch., Shen Ya. Foreign Direct Investment and Economic Growth - the Importance of Institutions and Urbanization. Economic Development and Cultural Change, 2003, no. 51, iss. 4, pp. 883-896.

11. Hsu M.-S., Lai Yu.-Lu., Lin F.-J. Effects of Industry Clusters on Company Competitiveness: Special Economic Zones in Taiwan. Review of Pacific Basin Financial Markets and Policies, 2013, no. 16, iss. 3, pp. 45-47.

12. Levien M. The Land Question: Special Economic Zones and the Political Economy of Dispossession in India. The Journal of Peasant Studies, 2012, no. 39, pp. 3-4.

13. Park B.-G. Spatially Selective Liberalization and Graduated Sovereignty: Politics of Neo-liberalism and 'Special Economic Zones' in South Korea. Political Geography Description, 2005, no. 24, iss. 7, pp. 850-873.

14. Schweinberger A. Special Economic Zones and Quotas on Imported Intermediate Goods: a Policy Proposal. Oxford Economic Papers, 2003, no. 55, iss. 4, pp. 696-715.

15. Skelholt A., Thune T. Coping with Economic Crises - The Role of Clusters. European Planning Studies, 2013, no. 22, iss. 10, pp. 1993-2010.

16. Tracey P., Heide J.B., Bell S.J., Governance P. Bringing 'Place' Back. Regional Clusters, Project Governance, and New Product Outcomes. Journal of Marketing, 2014, no. 78, pp. 1-16. DOI: https://doi.org/ 10.1509/jm.13.0524.

17. Wang J. The Economic Impact of Special Economic Zones: Evidence from Chinese Municipalities. Journal of Development Economics, 2013, no. 101, pp. 133-147. 


\section{УПРАВЛЕНИЕ ЭКОНОМИЧЕСКИМ РАЗВИТИЕМ}

\section{Information about the Authors}

Svetlana G. Pyankova, Doctor of Sciences (Economics), Associate Professor, Department of Regional, Municipal Economics and Management, Ural State University of Economics, 8 Marta St., 62 / Narodnoy Voli St., 45, 620144 Ekaterinburg, Russian Federation, silen_06@list.ru.

Olga T. Ergunova, Candidate of Sciences (Economics), Associate Professor, Department of Regional, Municipal Economics and Management, Ural State University of Economics, 8 Marta St., 62, office 655, 620000 Ekaterinburg, Russian Federation, ergunova-olga@yandex.ru.

Inna A. Mitrofanova, Candidate of Sciences (Economics), Associate Professor, Department of Economics and Management, Volgograd State Technical University, Prosp. Lenina, 28, 400005 Volgograd, Russian Federation, mia05011986@yandex.ru.

\section{Информация об авторах}

Светлана Григорьевна Пьянкова, доктор экономических наук, доцент кафедры региональной, муниципальной экономики и управления, Уральский государственный экономический университет, ул. 8 Марта, 62 / Народной Воли, 45, 620144 г. Екатеринбург, Российская Федерация, silen_06@list.ru.

Ольга Титовна Ергунова, кандидат экономических наук, доцент кафедры региональной, муниципальной экономики и управления, Уральский государственный экономический университет, ул. 8 Марта, 62, офис 655, 620000 г. Екатеринбург, Российская Федерация, ergunovaolga@yandex.ru.

Инна Алексеевна Митрофанова, кандидат экономических наук, доцент кафедры экономики и управления, Волгоградский государственный технический университет, просп. Ленина, 28, 400005 г. Волгоград, Российская Федерация, mia05011986@yandex.ru. 